\title{
Quality of life of transplanted children and their parents: a cross- sectional study
}

\author{
Pauline Duvant \\ Assistance Publique Hopitaux de Marseille \\ Magali Fillat \\ Assistance Publique Hopitaux de Marseille \\ Florentine Garaix \\ Assistance Publique Hopitaux de Marseille \\ Bertrand Roquelaure \\ Assistance Publique Hopitaux de Marseille \\ Caroline Ovaert \\ Assistance Publique Hopitaux de Marseille \\ Virginie Fouilloux \\ Assistance Publique Hopitaux de Marseille \\ Michel Tsimaratos \\ Assistance Publique Hopitaux de Marseille \\ Pascal Auquier \\ Aix-Marseille Universite \\ Alexandre Fabre \\ Assistance Publique Hopitaux de Marseille \\ Karine Baumstarck ( $\square$ karine.baumstarck@univ-amu.fr) \\ Health Service Research and Quality of Life Center Aix-Marseille Univ, Marseille, France
}

\section{Research}

Keywords: Transplant organ, paediatric, children, quality of life, parents

Posted Date: February 3rd, 2020

DOI: https://doi.org/10.21203/rs.2.22475/v1

License: @ (i) This work is licensed under a Creative Commons Attribution 4.0 International License. Read Full License

Version of Record: A version of this preprint was published at Orphanet Journal of Rare Diseases on August 17th, 2021. See the published version at https://doi.org/10.1186/s13023-021-01987-y. 


\section{Abstract}

\section{Background.}

Transplantation is a saving therapeutic that has heavy consequences. The quality of life (QoL) of transplanted children and their parents has been little studied and should help physicians better manage these patients. The objectives of the study were to assess: i) the QoL of transplanted children and parents and compare it with that of children with other chronic conditions associated with long-term consequences, and ii) potential variables modulating the QoL.

\section{Methods.}

This cross-sectional study was performed in a multidisciplinary paediatric unit (Timone Hospital, Marseille, France). Children were less than 18 years old; had a liver, kidney or heart transplant; and had a time since transplantation of 1 to 10 years. Sociodemographics and clinical data were recorded from medical forms. The QoL was assessed using the VSP-A (Vécu et Santé Perçue de l'Adolescent et de l'Enfant) and the WhoQoL self-reported questionnaires.

\section{Results.}

Forty-five families were included (response rate: 76\%). The transplanted organs were the liver for 20 children, the kidney for 15 children, and the heart for 10 children. The QoL of transplanted children reported by their parents was better than that of children with inborn errors of metabolism and similar to that of childhood leukaemia survivors. The QoL of parents of transplanted children was better than that of parents of children with inborn errors of metabolism and did not differ from French norms. The QoL did not differ according to the nature of the transplanted organ, sex or the main sociodemographic data. The main modulators decreasing QoL were residual treatment level, medications switch and the presence of another regular treatment.

\section{Conclusion.}

Transplanted children and their families reported moderate deterioration of their QoL compared with children with other chronic health conditions. Special attention should be given to QoL modulators related to therapeutic management (medication switches, regular treatments) that might be amenable to improve the QoL.

\section{Background}

Paediatric organ transplantation is now a standard treatment for end-stage disease. The survival rate afterwards transplantation may be up to $80 \% 5$ years after (1-4). Transplantation is not a curative treatment and after, the ongoing chronic illness remains present, with daily immunosuppressive treatment and potential unpleasant side effects, fear of organ dysfunction, and the need for continuous medical supervision (5). Organ transplantation for children, due to its occurrence during physical and mental development, causes major lifestyle disruptions in the everyday lives of patients and their families $(6,7)$ impacting their quality of life (QoL) (8).

The study of the QoL of transplanted children and their parents and the identification pf potential factors of QoL modulation should help to better manage these populations. Among the studies exploring the QoL of transplanted children, the findings are conflicting. In comparison with healthy populations, the QoL of transplanted paediatric patients could be lower $(2,5,9-13)$, closer or higher $(5,9$, 14-16), with children's QoL often being lower and adolescents' QoL being higher. Compared to other chronic conditions, the results are also discordant, with some studies showing better $(17,19)$, similar $(13,18,19)$ or lower QoL $(11)$. Three studies in the literature explored the QoL of parents of transplanted children $(11,15,20)$ : they show deteriorated QoL in comparison with the general population (15) and more mental health problems (11). Most of these studies analysed the transplantations of one organ type, liver or kidney, which limits the practical application of the results due to a low number of patients. Indeed, organ transplantation is rare, and transplantation centers have only a few patients. In our hospital in Marseille, France, all heart, liver and kidney transplanted children are followed up in the same unit and are taking care of by the same team. Follow-up and the management of immunosuppression are similar in many points. 
For the first time in France, we studied the QoL of a large sample of transplanted children including liver, kidney, and heart transplanted children, and their parents. We compared, using well-validated self-reported questionnaires, their QoL with that of samples of individuals presenting other various health conditions. The objectives of our study were: i) to assess the QoL levels of the transplanted children and their parents and to compare it with those of individuals with other chronic conditions associated with long-term consequences (childhood leukaemia survivors and children with inborn errors of metabolism), and ii) to assess the potential factors modulating the QoL of children and their parents.

\section{Methods}

\section{- Study design and population}

This study incorporated a cross-sectional design performed at the multidisciplinary paediatric centre of a French public teaching hospital (La Timone, Marseille, France). Children and their parents were included. The inclusion criteria were as follows: 1) for children: child with a history of organ transplantion (liver, kidney, or heart) transplanted for more than 1 year and less than 10 years, born between 1998 and 2011, with parents or legal guardians authorizing participation in the study; and 2) for parents: parents of a predefined child. A medical database allowed the identification of eligible children according to the selection criteria. The study was proposed to consecutive parents and children during a planned routine visit between June and November 2015.

\section{- Ethical aspects}

The protocol was approved by the ethics committee of Aix-Marseille University, France (reference number: 2014-08-04-03). According to French law (Article L1121-1, Law n²011-2012 29 December 2011, art. 5), all children and parents were fully informed of the study. This study was conducted in accordance with the Declaration of Helsinki and French Good Clinical Practices. Written consent was collected for each included parent.

\section{- Medical records}

For the children, the following data were collected: 1 . sociodemographic: sex and age of the child and school retardation ; 2 . clinical data: the nature of the transplanted organ (liver, kidney, or heart), the age at transplantation, the time since transplantation, the occurrence of a transplant rejection (biopsy), post-transplantation radiointervention or surgery, background treatment, regular treatment (treatment other than the immunosuppressive therapy), immunosuppressive medication switch,test residual treatment level (satisfactory, unsatisfactory), and the number of hospitalizations after transplantation.

For the parents the following sociodemographic data were collected: age, gender (mother or father), marital status (single, couple), and professional status (worker, non-worker). The number of siblings was also recorded.

\section{- Evaluation of quality of life}

\section{1) Children}

The QoL of the children and adolescents was assessed using a structured standardized questionnaire named the Vécu et Santé Perçue de l'Adolescent et de l'Enfant (VSP-A) $(21,22)$. The parent version, VSP-Ap, is designed to be answered by the parents of children or adolescents of all ages (from 4 to 18 years). The 37 items describe 10 dimensions : relations with parents (RPa), body image (BI), vitality (VIT), relations with friends (RFr), leisure activities (LEI), psychological well-being (PsWB), physical well-being (PhWB), school performance (SCH); relations with teachers (RT), and relations with medical staff (RMS). All scores range between 0 and 100, with higher scores indicating a better QoL. Two child versions (VSP-Ac for children aged 8 to 10 years and VSP-At for teenagers aged 11 to 17 years) and one parent version are available. In the two child versions, 7 dimensions were common (VSP-A): relations with parents/family (RFa), body image/self-esteem (BI), vitality (VIT), relations with friends (RFr), leisure activities (LEI), school performance (SCH), and relations with medical staff (RMS). The scores of children with chronic conditions associated with long-term consequences are also available from previous studies coordinated by our team: childhood leukaemia survivor children (23) and children with inborn errors of metabolism with restricted diet (24).

2) Parents 
Parents' QoL was assessed using the French version of the World Health Organization Quality of Life (WhoQoL-BREF) questionnaire, which is a generic questionnaire of 26 items used worldwide (25) that describes four domains: physical health, psychological health, social relationships, and environment. French norms are available only for three domains: physical health, psychological health, and social relationships (26). The scores of parents of children with inborn errors of metabolism with restricted diet are also available (24).

\section{Statistical analysis}

Continuous variables were expressed as the means and standard deviations or the medians and interquartile ranges (IQR). Qualitative variables were expressed as numbers and percentages. Nonparametric statistics were used. The VSPA-p scores were compared with the scores obtained from French parents of children suffering from inborn errors of metabolism with restricted diet (24) and French parents of childhood leukemia survivors (23). The VSP-A scores of the children and adolescents were compared to the scores obtained from French childhood leukaemia survivors (23). The WhoQoL scores of the parents were compared with the scores obtained from French parents of children suffering from of inborn errors of metabolism with restricted diet (24) and from French age-sex-crossed norms (26). Comparisons of mean QoL scores between different subgroups were performed using the Mann-Whitney tests for qualitative variables and Spearman's correlation coefficients for quantitative variables. The statistical analyses were performed using the SPSS software package, version 20.0 (SPSS Inc., Chicago, IL, USA). All tests were two-sided. Statistical significance was defined as $p<0.05$.

\section{Results}

Among 89 eligible families, 30 met an exclusion criterion and 14 families did not participate. Forty-five patients were included leading to a response rate of $76 \%$. The respondents and non-respondents did not differ according to the nature of the transplanted organ, age, and sex. Among the 45 patients, twenty children received a liver transplant, 15 received a kidney transplant, and 10 received a heart transplant. The median age at the time of the study was 9 years [IQR 6-12] and that at transplantation was 54 months [IQR 22-91]. The median time since transplantation was 52 [IQR 29-75] months. Nineteen children had a transplant rejection, 16 had a reoperation, and 28 had a radio-interventional procedure. At the evaluation time, 9 children had a residual level of treatment not in the target range, 28 had an immunosuppressive medication switch and 28 had a treatment other than the immunosuppressive therapy (regular treatment). Fourteen children presented a school delay greater than 1 year.

The participating parents were mothers for $73 \%$ of patients with a median age of 42 [IQR 38-47] years. Parents were in couples in $78 \%$ of cases. All characteristics are detailed in Table 1.

\section{Quality of life of transplanted children compared with that of other populations}

- Quality of life of children reported by the parents

The VSP-Ap scores of transplanted children did not differ from those of childhood leukaemia survivors, except for scores for leisure activities, where childhood leukaemia survivors reported significantly higher scores and scores for relationships with medical care providers, which were lower than those of childhood leukaemia survivors. In contrast, compared to children suffering from inborn errors of metabolism with restricted diet, the QoL scores of transplanted children were significantly better for leisure activities, relationships with friends, vitality, and relationships with family. The details are presented in Figure 2.

- Self-reported quality of life of children

We observed that the QoL levels of transplanted young children (6-10 years) were: 1) higher than the QoL levels of children suffering from inborn errors of metabolism with restricted diet, except for school performance and leisure activities; and 2) lower than the QoL levels of childhood leukaemia survivors, except for vitality. In the same way, we saw that the QoL levels of transplanted teenagers (11-18 years) were: 1) higher than the QoL levels of children suffering from inborn errors of metabolism with restricted diet, except for 2 of the 9 dimensions (relationships with teachers and relationships with family); and 2) higher than the QoL levels of childhood leukaemia survivors for 7 of the 9 dimensions. Because of a limited number of cases (only 18 children aged from 6 to 10 years and 12 teenagers aged from 11 to 18 answered the VSP-A), we did not perform statistics to compare QoL levels with other populations. All the details are provided in the additional material (additional files 1 and 2). 
- Quality of life of parents

The QoL of parents of transplanted children did not differ from that of parents of children suffering from inborn errors of metabolism with restricted diet and from that of French age-sex-crossed norms. All the details are provided in Figure 3.

\section{Variables modulating the quality of life}

- Quality of life of transplanted children reported by their parents

The factors significantly associated with QoL scores were as follows: i) older children at the time of study reported better relationships with teachers than younger children; ii) the body image score was lower for older children at the time of the study and at transplant, for children of parents with a lower educational level, and for children with more siblings; iii) relationships with friends and leisure activities were better for children of parents with a job; iv) radiointervention was associated with a lower school score; v) QoL scores did not differ according to the nature of the transplanted organ, except for the vitality score which was lower for children with a kidney transplant; vi) the occurence of a medication switch in immunosuppression decreased scores for leisure activities and school performances; vii) an unsatisfactory residual treatment level was associated with better scores for relationship with family and vitality. Sex of the child, school retardation, parental marital status, parental age, time since transplantation, rejection, and reoperation were not associated to QoL. All the results are provided in Table 2.

- Self-reported quality of life of transplanted children

The scores for the 7 common dimensions between the child version and the teenager version were available for 28 individuals. The factors associated with QoL scores were as follows: i) older children at the time of the study had better scores for relationships with friends and school performance; ii) the absence of school retardation was associated with a better score relationship with friends; iii) older parents had better scores for relationships with family; iii) when the 2 parents were a couple, the scores for relationships with medical care providers were significantly better; iv) children with more siblings had better scores for body image; v) older children at transplantation had better scores for relationships with friends; vi) children with longer times since transplantation had higher school performance scores; vii) the occurrence of a medication switch was associated with lower leisure activities scores; viii) children with no regular treatment had higher body image scores. The QoL scores did not differ according to the gender of the child, parental education level and professional status, the nature of the transplanted organ, rejection/reoperation/radiointervention and residual treatment level. All the results are detailed in Table 3.

- Quality of life of parents of transplanted children

An unsatisfactory residual treatment level was associated with a better quality of life in the physical dimension. No other variable was associated with parents QoL. All the results are detailed in Additional file 3.

\section{Discussion}

We have studied the quality of life and the modulating factors of a sample of 45 transplanted children and their parents, including, for the first time, liver, kidney, and heart transplanted children together.

A first interesting finding is that the QoL of transplanted children (as reported by their parents or by themselves) did not differ regarding the organ type. Two other studies $(27,28)$ did not find significant differences between liver and kidney transplant recipients. Most likely after transplantation, the specificity of the organ becomes less important, and daily life becomes similar to that of individuals with another chronic condition. The immunosuppressive drugs and follow-up are almost the same for these three organ transplantations. This similar QoL may also be explained by the specificity of the centre where the study was conducted. After the transplantation procedure, all children and families are managed in the same care unit by the same team. This unit offers medical, psychological, and social support in the same location, allowing care standardization and resource sharing. Scores for relationships with medical care providers, higher for the transplanted children than for childhood leukaemia survivors, suggest that this kind of organization satisfies the families. The multidisciplinary staff is trained to coordinate and optimize the care trajectory. Families may have access to familiar professionals that improve understanding and faith. Some common educational therapy workshops could be put into place to offer self-knowledge and support to children and their parents.

Page 5/16 
In our study, we compared our sample to children with other conditions: childhood leukaemia survivors and children suffering from inborn errors of metabolism. Children's QoL reported by parents was close to the QoL reported by childhood leukaemia survivors, which had been described in other studies $(19,29)$, and was better than, for most dimensions, the QoL of children suffering from inborn errors of metabolism with restricted diet. Some hypotheses could be made. While the period around the transplantation process may be considered critical, after transplantation, everyday life progressively becomes close to a "normal life". With time, the occurrence of severe, fatal and lethal events decreases, reducing emotional and physical impacts. The course of disease at this point of a transplanted individual looks similar to that of a person with acute leukaemia: daily life gradually normalizes as the person transitions out of the acute therapeutic period. Transplanted children do not heal, but the disease burden often decreases. In contrast, children suffering from inborn errors of metabolism with restricted diet are confronted daily and continuously with the disease and its consequences. A lethal risk is often present and leads to permanent stress. Limbers et al (19) demonstrated similar findings in a liver transplant cohort: QoL was better than that in children on renal dialysis, similar to that in renal transplantation patients and patients in cancer remission. Taylor et al (13), also in a cohort of liver transplant children, found that the QoL was similar to that of individuals with other chronic situations, such as asthma and diabetes.

Parents' QoL did not differ from the QoL of parents of children suffering from inborn errors of metabolism with restricted diet, or, more surprisingly, from French (age-sex-crossed) norms. This finding could be partially explained by the presence of a well-known phenomenon: 'response shift' or 'adaptation to illness' or 'coping' (30). Coping is commonly defined as the cognitive and behavioural efforts that are implemented to solve problems and to reduce the stress that these problems may cause. In many various chronic diseases (31-34), it has been shown that self-reported QoL is not associated with objective health status due to the ability of individuals to adapt to manage the realities life. Because they have known the diagnosis for several years or since their child's birth, parents adapt themselves to the illness over time and thus report corresponding QoL. Due to a lack of reference we did not compare QoL of parents in our sample to that of parents of leukaemia survivors. In the future, it could also be interesting to study how patients and caregivers handle problems in daily life and their ability to cope with difficulties.

The last part of our findings refers to QoL determinants. The identification of QoL determinants may help to find unmet needs, prioritize service improvements, and support funding decisions. The analyses that we performed showed that the main sociodemographic and socioeconomic parameters (such as gender, parent's marital status, and parent's educational level) cannot be identified as significant QoL determinants. QoL scores were not associated with the nature of the transplant organ while the notion of medication switch or residual level range seemed to be more important modulators. These findings suggest that organ transplantation, whatever the nature of the organ, may be considered as a global and homogeneous chronic condition. We only found ectopic associations, expected or not. Not surprisingly, older children (and similarly later transplanted children) reported better QoL levels in their relationship with friends and lower levels in their relationship with teachers, reflecting the expected relationships during the specific time of adolescence. Children with longer times since transplantation had better school scores, explained by the effect of the transplantation procedure on daily activities of the child including school. Radiointervention was associated with a lower school score. Health care teams should reinforce actions to disrupt school less. In their study on liver recipients, Alonso et al (35) found similar findings, with the occurrence of reoperations and diabetes post transplantation impacting the QoL.

Long-term therapeutic necessity appears common in these conditions, disrupting everyday life and free time. The necessity to change a treatment for intolerance or inefficacy, and the necessity of residual treatment level control are parameters that disturb the QoL. The occurance of a medication switch decreased scores for leisure activities and school performance. Medications and several appointments can prevent children from eating lunch at school or from doing some outdoor school activities. Each change in the treatment requires several blood tests and consultations at the hospital. Health care providers must adapt their practice to the child and family, not the inverse. The fact that a residual of treatment not in the target is associated with better relationship between children and their family and parents' physical well-being suggests that treatment that impacts daily life less, results in better QoL. Self-knowledge of signs and symptoms of transplant rejection or other complications should be learned by children and their families in order to consult their treatment providers early and to avoid heavy treatment or hospitalization.

\section{Strengths And Limitations}


One strength of the study is the nature of QoL questionnaire's used. They have interesting characteristics in comparison with previous studies: i) their content is based on patients' or family's point of view, known to provide more valid information than contents based on experts' point of view (36); ii) the validation process is based on a well-established procedure while previous studies used tools based on incomplete (or inappropriate) validation processes.

Additionally, our study is one of the first to study parents' QoL, although they are the primary caregivesr for most children.

Another strength is that we assessed for the first time heart transplanted children. Only two studies provide data from French population $(5,14)$ with a kidney and liver transplant cohort. The transferability of findings of the non-French population is difficult because the QoL and satisfaction are closely dependent on cultural background and the health-care system. Free choice of healthcare and universal health-care insurance are particular to France and lead to variations in patients' and families' expectations (37). Almost all the health care system is free in France which might explain that why sociodemographic parameters do not impact the QoL.

One limitation of the study is our sample size, which did not allow for a multivariate approach. Potential confounding factors and moderate associations were possibly missed due to low power.eplication of these findings in larger groups of patients is required.

Due to the participation rate, the representativeness of our study could be questioned. We could hypothesize that the nonparticipants included families of children with more severe physical and/or mental conditions, which would have led to a global overestimation of the quality of life. However, the respondents did not differ from the non-respondents in terms of the main characteristics (sociodemographic and clinical), which ensures the relative validity of our findings. Fewer liver transplant children were included in comparison with other organ transplant children, but this can be explained by the fact that this transplant requires fewer hospital visits and children were seen less during the inclusion period.

The last limitation is the type of study which is cross-sectional. Cross-sectional studies examine individuals with heterogeneous disease durations. Longitudinal studies provide more valid information and are necessary to more precisely determine the weights of potential predictive factors of the quality of life. Future studies based on longitudinal cohorts will help to better understand families' functioning.

\section{Conclusion}

Children and their families reported moderate deterioration of their QoL in comparison with those with other chronic health conditions. While the nature of the transplanted organ was not identified as a QoL modulator, special attention should be given to therapeutic management which might be amenable and is expected to improve the QoL.

\section{References}

1. Kim JJ, Marks SD. Long-term outcomes of children after solid organ transplantation. Clinics (Sao Paulo). 2014;69 Suppl 1:2838.

2. LaRosa C, Baluarte HJ, Meyers KE. Outcomes in pediatric solid-organ transplantation. Pediatr Transplant. 2011;15(2):128-41.

3. Smith JM, McDonald RA. Progress in renal transplantation for children. Adv Ren Replace Ther. 2000;7(2):158-71.

4. Yazigi NA. Long term outcomes after pediatric liver transplantation. Pediatr Gastroenterol Hepatol Nutr. 2013;16(4):207-18.

5. Manificat S, Dazord A, Cochat P, Morin D, Plainguet F, Debray D. Quality of life of children and adolescents after kidney or liver transplantation: child, parents and caregiver's point of view. Pediatr Transplant. 2003;7(3):228-35.

6. Zitelli BJ, Miller JW, Gartner JC, Jr., Malatack JJ, Urbach AH, Belle SH, et al. Changes in life-style after liver transplantation. Pediatrics. 1988;82(2):173-80.

7. Rodrigue JR, MacNaughton K, Hoffmann RG, 3rd, Graham-Pole J, Andres JM, Novak DA, et al. Transplantation in children. A longitudinal assessment of mothers' stress, coping, and perceptions of family functioning. Psychosomatics. 1997;38(5):47886.

8. Tarter RE, Switala J, Arria A, Van Thiel DH. Impact of liver disease on daily living in transplantation candidates. J Clin Epidemiol. 1991;44(10):1079-83. 
9. Dehghani SM, Imanieh MH, Honar N, Haghighat M, Astaneh B, Bahador A, et al. Evaluation of quality of life in children six months after liver transplantation. Middle East J Dig Dis. 2012;4(3):158-62.

10. Araujo NSS, Pereira RRF, Fram D, Hino P, Longo MCB, Taminato M. Quality of life in children with kidney transplant: Systematic review. Rev Bras Enferm. 2018;71(suppl 6):2818-23.

11. Diseth TH, Tangeraas T, Reinfjell T, Bjerre A. Kidney transplantation in childhood: mental health and quality of life of children and caregivers. Pediatr Nephrol. 2011;26(10):1881-92.

12. Miserachs M, Parmar A, Bakula A, Hierro L, D'Antiga L, Goldschmidt I, et al. Health-related quality of life in pre-adolescent liver transplant recipients with biliary atresia: A cross-sectional study. Clin Res Hepatol Gastroenterol. 2019;43(4):427-35.

13. Taylor RM, Franck LS, Gibson F, Donaldson N, Dhawan A. Study of the factors affecting health-related quality of life in adolescents after liver transplantation. Am J Transplant. 2009;9(5):1179-88.

14. Roblin E, Audhuy F, Boillot O, Rivet C, Lachaux A. [Long-term quality of life after pediatric liver transplantation]. Arch Pediatr. 2012;19(10):1039-52.

15. Sundaram SS, Landgraf JM, Neighbors K, Cohn RA, Alonso EM. Adolescent health-related quality of life following liver and kidney transplantation. Am J Transplant. 2007;7(4):982-9.

16. Apajasalo M, Rautonen J, Sintonen H, Holmberg C. Health-related quality of life after organ transplantation in childhood. Pediatr Transplant. 1997;1(2):130-7.

17. Taylor R, Franck LS, Gibson F, Dhawan A. A critical review of the health-related quality of life of children and adolescents after liver transplantation. Liver Transpl. 2005;11(1):51-60; discussion 7-9.

18. Parmar A, Vandriel SM, Ng VL. Health-related quality of life after pediatric liver transplantation: A systematic review. Liver Transpl. 2017;23(3):361-74.

19. Limbers CA, Neighbors K, Martz K, Bucuvalas JC, Webb T, Varni JW, et al. Health-related quality of life in pediatric liver transplant recipients compared with other chronic disease groups. Pediatr Transplant. 2011;15(3):245-53.

20. Hamasaki Y, Yamaguchi T, Takahashi Y, Hashimoto J, Muramatsu M, Kawamura T, et al. Change in the quality of life of caregivers of pediatric department patients undergoing kidney transplantation: a single-center prospective study. Clin Exp Nephrol. 2018;22(5):1198-204.

21. Simeoni MC, Auquier P, Antoniotti S, Sapin C, San Marco JL. Validation of a French health-related quality of life instrument for adolescents: the VSP-A. Qual Life Res. 2000;9(4):393-403.

22. Sapin C, Simeoni MC, El Khammar M, Antoniotti S, Auquier P. Reliability and validity of the VSP-A, a health-related quality of life instrument for ill and healthy adolescents. J Adolesc Health. 2005;36(4):327-36.

23. Michel G, Bordigoni P, Simeoni MC, Curtillet C, Hoxha S, Robitail S, et al. Health status and quality of life in long-term survivors of childhood leukaemia: the impact of haematopoietic stem cell transplantation. Bone Marrow Transplant. 2007;40(9):897904.

24. Fabre A, Baumstarck K, Cano A, Loundou A, Berbis J, Chabrol B, et al. Assessment of quality of life of the children and parents affected by inborn errors of metabolism with restricted diet: preliminary results of a cross-sectional study. Health Qual Life Outcomes. 2013;11:158.

25. WHOQOL. Group. Development of the World Health Organization WHOQOL-BREF quality of life assessment. The WHOQOL Group. Psychol Med. 1998;28(3):551-8.

26. Baumann C, Erpelding ML, Regat S, Collin JF, Briancon S. The WHOQOL-BREF questionnaire: French adult population norms for the physical health, psychological health and social relationship dimensions. Rev Epidemiol Sante Publique. 2010;58(1):33-9.

27. Devine KA, Reed-Knight B, Loiselle KA, Simons LE, Mee LL, Blount RL. Predictors of long-term health-related quality of life in adolescent solid organ transplant recipients. J Pediatr Psychol. 2011;36(8):891-901.

28. Haavisto A, Korkman M, Sintonen H, Holmberg C, Jalanko H, Lipsanen J, et al. Risk factors for impaired quality of life and psychosocial adjustment after pediatric heart, kidney, and liver transplantation. Pediatr Transplant. 2013;17(3):256-65.

29. Fredericks EM, Lopez MJ, Magee JC, Shieck V, Opipari-Arrigan L. Psychological functioning, nonadherence and health outcomes after pediatric liver transplantation. Am J Transplant. 2007;7(8):1974-83. 
30. Schwartz CE, Bode R, Repucci N, Becker J, Sprangers MA, Fayers PM. The clinical significance of adaptation to changing health: a meta-analysis of response shift. Qual Life Res. 2006;15(9):1533-50.

31. Li Y, Schwartz CE. Data mining for response shift patterns in multiple sclerosis patients using recursive partitioning tree analysis. Qual Life Res. 2011;20(10):1543-53.

32. Boucekine M, Boyer L, Baumstarck K, Millier A, Ghattas B, Auquier P, et al. Exploring the response shift effect on the quality of life of patients with schizophrenia: an application of the random forest method. Med Decis Making. 2015;35(3):388-97.

33. Boucekine M, Loundou A, Baumstarck K, Minaya-Flores P, Pelletier J, Ghattas B, et al. Using the random forest method to detect a response shift in the quality of life of multiple sclerosis patients: a cohort study. BMC Med Res Methodol. 2013;13:20.

34. Baumstarck K, Leroy T, Hamidou Z, Tabouret E, Farina P, Barrie M, et al. Coping with a newly diagnosed high-grade glioma: patient-caregiver dyad effects on quality of life. J Neurooncol. 2016;129(1):155-64.

35. Alonso EM, Martz K, Wang D, Yi MS, Neighbors K, Varni JW, et al. Factors predicting health-related quality of life in pediatric liver transplant recipients in the functional outcomes group. Pediatr Transplant. 2013;17(7):605-11.

36. Britten N. Qualitative interviews in medical research. BMJ. 1995;311(6999):251-3.

37. Baider L, Ever-Hadani P, De-Nour AK. The impact of culture on perceptions of patient-physician satisfaction. Isr J Med Sci. 1995;31(2-3):179-85.

\section{Declarations}

\section{- Ethics approval and consent to participate}

The protocol was approved by the ethics committee of Aix-Marseille University, France (reference number: 2014-08-04-03). According to the French law (Article L1121-1, Law n²011-2012 29 december 2011, art. 5), all children and parents were fully informed of the study. Written consent was collected for each included parent.

\section{- Consent for publication}

Not applicable.

\section{- Availability of data and materials}

The datasets used and/or analyzed during the current study are available from the corresponding author on reasonable request.

\section{- Competing interests}

The authors declare that they have no competing interest.

\section{- Funding}

No funding.

\section{- Authors' contributions}

Conception and design: PD, MF, AF, KB.

Study coordination: AF, KB.

Acquisition of data: MF, FG, BR, CO, VF, MT.

Analysis of data: PD, MF, KB.

Interpretation of data: PD, MF, MT, PA, AF, KB.

Drafting and writing of manuscript: $P D, M F, A F, K B$.

Approval of final version of the manuscript: all authors. 
- Acknowledgments

The authors are grateful to all the subjects for their participation in the study.

\section{Tables}

Table 1. Participants characteristics

\begin{tabular}{|c|c|c|}
\hline \multicolumn{2}{|l|}{ 1. Children } & $\begin{array}{c}\mathrm{N}=45 \\
\mathrm{~N}(\%) \text { or med [IQR] }\end{array}$ \\
\hline \multirow[t]{2}{*}{ Gender } & Girls & $19(42,2)$ \\
\hline & Boys & $26(57,8)$ \\
\hline Age (years) & & $9,3[5,6-12,4]$ \\
\hline \multirow[t]{3}{*}{ School level } & Not schooled & $2(4,4)$ \\
\hline & Appropriate level & $29(64,4)$ \\
\hline & Retardation* & $14(31,1)$ \\
\hline \multirow[t]{3}{*}{ Siblings } & No & $4(9,1)$ \\
\hline & Yes & $40(90,9)$ \\
\hline & Number & $2,0[1,0-2,0]$ \\
\hline \multirow[t]{3}{*}{ Transplant organ } & Liver & $20(44,4)$ \\
\hline & Kidney & $15(33,3)$ \\
\hline & Heart & $10(22,2)$ \\
\hline Age at transplant (months) & & $53,8[21,7-90,6]$ \\
\hline Delay from the transplant (months) & & $51,7[28,6-74,6]$ \\
\hline \multirow[t]{2}{*}{ Graft rejection } & Yes & $19(43,2)$ \\
\hline & No & $25(56,8)$ \\
\hline \multirow[t]{2}{*}{ Reject type } & Acute rejection & $15(83.3)$ \\
\hline & Chronic rejection & $2(11.1)$ \\
\hline \multirow[t]{2}{*}{ Reoperation } & Yes & $16(36,4)$ \\
\hline & No & $28(63,6)$ \\
\hline \multirow[t]{2}{*}{ Radio-interventionel procedure } & Yes & $28(65,1)$ \\
\hline & No & $15(34,9)$ \\
\hline Total number of medications & & $3,0[2,0-5,0]$ \\
\hline \multirow{2}{*}{ Number of immunosuppresive drugs } & 1 & $17(39,5)$ \\
\hline & $>=2$ & $26(60,5)$ \\
\hline \multirow[t]{2}{*}{ Residual treatment level } & Satisfactory & $31(77,5)$ \\
\hline & Not satisfactory & $9(22,5)$ \\
\hline \multirow[t]{2}{*}{ Immunosuppressive medication switch } & Yes & $28(65,1)$ \\
\hline & No & $15(34,9)$ \\
\hline \multirow[t]{2}{*}{ Regular treatment** } & Yes & $28(65,1)$ \\
\hline & No & $15(34,9)$ \\
\hline \multirow[t]{2}{*}{ 2. Parents } & & $\mathrm{N}=45$ \\
\hline & & $\mathrm{N}(\%)$ or med [IQR] \\
\hline \multicolumn{2}{|l|}{ Mother } & $33(80,5)$ \\
\hline \multicolumn{2}{|l|}{ Father } & $8(19,5)$ \\
\hline \multicolumn{2}{|l|}{ Age (years) } & $42,0[38,0-46,8]$ \\
\hline \multirow[t]{2}{*}{ Marital status } & Single & $9(20,5)$ \\
\hline & Couple & $35(79,5)$ \\
\hline \multirow[t]{2}{*}{ Educational level } & $<12$ years & $22(52,4)$ \\
\hline & $>=12$ years & $20(47,6)$ \\
\hline \multirow[t]{2}{*}{ Professional status } & Worker*** & $25(56,8)$ \\
\hline & Non-workers & $19(43,2)$ \\
\hline
\end{tabular}

* school retardation defined as one year retardation

**other treatment associated with immunosuppressive drug

*** at least one of the 2 parents

Med [IQR] median [interquartile range]

Table 2. Factors modulating children quality of life reported by parents (VSP-Ap): $N=45$ 


\begin{tabular}{|c|c|c|c|c|c|c|c|c|c|c|}
\hline & VIT & PsWB & $\mathrm{RFr}$ & LEI & $\mathrm{RPa}$ & PhWB & RT & $\mathrm{SCH}$ & BI & RMS \\
\hline \multicolumn{11}{|c|}{ Gender of the child } \\
\hline Boys & $80,1 \pm 13,8$ & $77,6 \pm 20,1$ & $56,8 \pm 29,4$ & $65,0 \pm 57,0$ & $79,0 \pm 13,2$ & $70,3 \pm 22,0$ & $76,1 \pm 24,8$ & $69,8 \pm 15,2$ & $76,3 \pm 16,5$ & $75,4 \pm 31,9$ \\
\hline Girls & $73,5 \pm 16,0$ & $79,0 \pm 15,7$ & $59,0 \pm 21,6$ & $57,7 \pm 22,0$ & $78,1 \pm 14,2$ & $74,7 \pm 19,7$ & $68,4 \pm 33,5$ & $64,8 \pm 18,9$ & $76,1 \pm 13,2$ & $68,1 \pm 32,7$ \\
\hline p-value & NS & NS & NS & NS & NS & NS & NS & NS & NS & NS \\
\hline $\begin{array}{l}\text { Age of the } \\
\text { child (R) } \\
\text { p-value }\end{array}$ & $\begin{array}{l}-0,243 \\
\text { NS }\end{array}$ & $\begin{array}{l}-0,146 \\
\text { NS }\end{array}$ & $\begin{array}{l}0,139 \\
\text { NS }\end{array}$ & $\begin{array}{l}-0,008 \\
\text { NS }\end{array}$ & $\begin{array}{l}-0,070 \\
\text { NS }\end{array}$ & $\begin{array}{l}-0,008 \\
\text { NS }\end{array}$ & $\begin{array}{l}-0,353 \\
\mathbf{0 , 0 3 0}\end{array}$ & $\begin{array}{l}-0,236 \\
\text { NS }\end{array}$ & $\begin{array}{l}-0,467 \\
0,002\end{array}$ & $\begin{array}{l}0,053 \\
\text { NS }\end{array}$ \\
\hline \multicolumn{11}{|c|}{ School retardation } \\
\hline No & $78,0 \pm 14,6$ & $77,5 \pm 19,6$ & $58,5 \pm 24,5$ & $63,6 \pm 53,2$ & $79,6 \pm 12,8$ & $73,1 \pm 20,6$ & $78,5 \pm 23,0$ & $71,0 \pm 15,2$ & $78,2 \pm 14,7$ & $65,7 \pm 36,2$ \\
\hline Yes & $75,4 \pm 16,9$ & $78,1 \pm 17,0$ & $55,8 \pm 31,0$ & $54,4 \pm 25,5$ & $77,5 \pm 15,6$ & $69,6 \pm 21,6$ & $66,3 \pm 35,1$ & $61,5 \pm 18,0$ & $70,2 \pm 14,7$ & $83,3 \pm 19,5$ \\
\hline $\mathrm{p}$-value & NS & NS & NS & NS & NS & NS & NS & NS & NS & NS \\
\hline \multicolumn{11}{|l|}{ Age of } \\
\hline p-value & NS & NS & NS & NS & NS & NS & NS & NS & NS & NS \\
\hline \multicolumn{11}{|c|}{ Parental marital status } \\
\hline Single & $76,9 \pm 21,7$ & $76,8 \pm 29,0$ & $49,2 \pm 32,2$ & $49,4 \pm 28,6$ & $79,4 \pm 21,4$ & $70,8 \pm 25,8$ & $70,8 \pm 33,3$ & $66,7 \pm 16,5$ & $77,1 \pm 17,5$ & $67,9 \pm 29,0$ \\
\hline Couple & $77,5 \pm 13,0$ & $78,3 \pm 16,1$ & $59,9 \pm 24,4$ & $65,0 \pm 48,2$ & $78,3 \pm 11,1$ & $72,1 \pm 20,2$ & $73,2 \pm 28,6$ & $68,1 \pm 17,0$ & $75,3 \pm 14,3$ & $73,2 \pm 33,0$ \\
\hline $\mathrm{p}$-value & NS & NS & NS & NS & NS & NS & NS & NS & NS & NS \\
\hline \multicolumn{11}{|c|}{ Parent' educational level } \\
\hline$<12$ years & $75,2 \pm 17,9$ & $76,0 \pm 22,1$ & $53,6 \pm 26,4$ & $55,2 \pm 24,2$ & $78,0 \pm 15,0$ & $70,7 \pm 23,9$ & $69,5 \pm 33,6$ & $68,2 \pm 14,3$ & $71,0 \pm 14,5$ & $80,8 \pm 23,4$ \\
\hline$>=12$ years & $80,0 \pm 11,2$ & $80,6 \pm 14,5$ & $61,4 \pm 26,4$ & $69,6 \pm 61,9$ & $78,5 \pm 12,3$ & $73,8 \pm 18,4$ & $74,5 \pm 24,5$ & $68,4 \pm 19,8$ & $80,2 \pm 14,5$ & $61,1 \pm 37,6$ \\
\hline p-value & NS & NS & NS & NS & NS & NS & NS & NS & 0,047 & NS \\
\hline \multicolumn{11}{|c|}{ Parent' professional status } \\
\hline Workers & $77,8 \pm 13,9$ & $79,4 \pm 16,3$ & $67,4 \pm 20,1$ & $71,9 \pm 53,8$ & $81,8 \pm 10,7$ & $70,6 \pm 17,3$ & $79,0 \pm 24,5$ & $68,5 \pm 17,6$ & $78,5 \pm 12,7$ & $67,0 \pm 37,9$ \\
\hline Not workers & $76,7 \pm 16,5$ & $76,0 \pm 21,5$ & $44,6 \pm 28,0$ & $48,7 \pm 25,7$ & $74,3 \pm 16,1$ & $73,4 \pm 25,6$ & $64,1 \pm 33,4$ & $66,9 \pm 15,9$ & $71,7 \pm 16,8$ & $79,7 \pm 19,7$ \\
\hline p-value & NS & NS & 0,014 & 0,047 & NS & NS & NS & NS & NS & NS \\
\hline $\begin{array}{l}\text { Siblings } \\
\text { number }\left(R^{\circ}\right)\end{array}$ & $\begin{array}{l}-0,301 \\
\text { NS }\end{array}$ & $\begin{array}{l}-0,154 \\
\text { NS }\end{array}$ & $\begin{array}{l}-0,141 \\
\text { NS }\end{array}$ & $\begin{array}{l}-0,124 \\
\text { NS }\end{array}$ & $\begin{array}{l}-0,159 \\
\text { NS }\end{array}$ & $\begin{array}{l}0,005 \\
\text { NS }\end{array}$ & $\begin{array}{l}-0,265 \\
\text { NS }\end{array}$ & $\begin{array}{l}-0,162 \\
\text { NS }\end{array}$ & $\begin{array}{l}-0,339 \\
0,035\end{array}$ & $\begin{array}{l}0,055 \\
\text { NS }\end{array}$ \\
\hline \multicolumn{11}{|l|}{ Transplant } \\
\hline Liver & $84,9 \pm 13,3$ & $84,1 \pm 18,1$ & $61,5 \pm 27,6$ & $55,7 \pm 19,0$ & $80,3 \pm 15,2$ & $73,0 \pm 21,5$ & $83,3 \pm 24,2$ & $70,6 \pm 16,5$ & $80,7 \pm 14,3$ & $70,4 \pm 34,0$ \\
\hline Kidney & $70,8 \pm 11,2$ & $74,9 \pm 16,1$ & $52,1 \pm 25,1$ & $70,5 \pm 72,9$ & $79,2 \pm 10,6$ & $72,1 \pm 19,7$ & $59,8 \pm 34,5$ & $61,6 \pm 17,3$ & $69,9 \pm 11,9$ & $78,5 \pm 27,6$ \\
\hline Heart & $72,2 \pm 17,6$ & $73,1 \pm 20,5$ & $60,6 \pm 26,0$ & $61,1 \pm 22,5$ & $74,8 \pm 14,6$ & $70,2 \pm 23,8$ & $75,0 \pm 20,4$ & $72,2 \pm 15,0$ & $77,1 \pm 18,5$ & $67,6 \pm 35,7$ \\
\hline p-value & 0,003 & NS & NS & NS & NS & NS & NS & NS & NS & NS \\
\hline \multicolumn{11}{|l|}{ transplant $\left(\mathrm{R}^{\circ}\right)$} \\
\hline p-value & NS & NS & NS & NS & NS & NS & NS & NS & $<0,001$ & NS \\
\hline $\begin{array}{l}\text { Delay from } \\
\text { transplant }\left(R^{\circ}\right) \\
p \text {-value }\end{array}$ & $\begin{array}{l}-0,112 \\
\text { NS }\end{array}$ & $\begin{array}{l}-0,036 \\
\text { NS }\end{array}$ & $\begin{array}{l}0,064 \\
\text { NS }\end{array}$ & $\begin{array}{l}-0,238 \\
\text { NS }\end{array}$ & $\begin{array}{l}0,086 \\
\text { NS }\end{array}$ & $\begin{array}{l}-0,004 \\
\text { NS }\end{array}$ & $\begin{array}{l}-0,203 \\
\text { NS }\end{array}$ & $\begin{array}{l}-0,110 \\
\text { NS }\end{array}$ & $\begin{array}{l}-0,032 \\
0,035\end{array}$ & $\begin{array}{l}-0,014 \\
\text { NS }\end{array}$ \\
\hline \multicolumn{11}{|l|}{ Graft rejection } \\
\hline Yes & $75,2 \pm 15,1$ & $76,4 \pm 17,4$ & $53,8 \pm 29,3$ & $49,4 \pm 19,8$ & $78,1 \pm 15,0$ & $72,8 \pm 17,5$ & $68,4 \pm 25,6$ & $66,4 \pm 18,1$ & $76,1 \pm 16,7$ & $78,6 \pm 28,0$ \\
\hline No & $78,4 \pm 15,1$ & $79,0 \pm 19,4$ & $59,5 \pm 23,6$ & $70,1 \pm 56,2$ & $78,9 \pm 12,7$ & $70,8 \pm 23,9$ & $76,2 \pm 32,0$ & $69,0 \pm 16,4$ & $76,1 \pm 14,4$ & $66,7 \pm 34,8$ \\
\hline p-value & NS & NS & NS & NS & NS & NS & NS & NS & NS & \\
\hline \multicolumn{11}{|l|}{ Reoperation } \\
\hline Yes & $78,1 \pm 16,5$ & $79,5 \pm 19,6$ & $67,0 \pm 24,5$ & $61,3 \pm 22,1$ & $82,0 \pm 13,1$ & $69,1 \pm 21,2$ & $79,8 \pm 30,8$ & $67,5 \pm 16,9$ & $76,9 \pm 11,9$ & $60,0 \pm 37,8$ \\
\hline No & $77,4 \pm 14,3$ & $76,9 \pm 17,9$ & $54,5 \pm 25,0$ & $63,7 \pm 54,8$ & $77,0 \pm 13,6$ & $73,5 \pm 21,4$ & $68,8 \pm 27,5$ & $67,7 \pm 17,3$ & $76,1 \pm 16,8$ & $79,3 \pm 26,2$ \\
\hline $\mathrm{p}$-value & NS & NS & NS & NS & NS & NS & NS & NS & NS & NS \\
\hline \multicolumn{11}{|c|}{ Radiointervention } \\
\hline Yes & $75,0 \pm 15,9$ & $75,2 \pm 19,8$ & $60,5 \pm 27,3$ & $55,8 \pm 23,3$ & $79,2 \pm 13,8$ & $69,3 \pm 23,1$ & $68,9 \pm 31,1$ & $63,0 \pm 15,8$ & $73,3 \pm 15,8$ & $69,1 \pm 32,9$ \\
\hline No & $83,3 \pm 12,2$ & $83,5 \pm 14,9$ & $55,3 \pm 22,3$ & $76,7 \pm 69,1$ & $79,2 \pm 13,5$ & $77,7 \pm 16,8$ & $82,6 \pm 19,9$ & $76,8 \pm 15,4$ & $82,7 \pm 12,5$ & $74,4 \pm 32,4$ \\
\hline p-value & NS & NS & NS & NS & NS & NS & NS & 0,020 & NS & NS \\
\hline \multicolumn{11}{|c|}{$\begin{array}{l}\text { Last residual treatment } \\
\text { level }\end{array}$} \\
\hline Satisfactory & $73,9 \pm 13,9$ & $79,7 \pm 18,2$ & $57,7 \pm 25,9$ & $66,2 \pm 52,4$ & $77,2 \pm 10,6$ & $71,7 \pm 23,1$ & $67,7 \pm 30,2$ & $67,6 \pm 16,4$ & $76,0 \pm 15,1$ & $74,1 \pm 32,1$ \\
\hline $\begin{array}{l}\text { Not } \\
\text { satisfactory }\end{array}$ & $87,6 \pm 13,1$ & $83,3 \pm 13,5$ & $64,3 \pm 28,8$ & $57,2 \pm 22,5$ & $86,8 \pm 12,1$ & $77,1 \pm 18,2$ & $88,1 \pm 22,5$ & $69,4 \pm 17,8$ & $79,6 \pm 17,2$ & $65,5 \pm 39,2$ \\
\hline $\mathrm{p}$-value & 0,025 & NS & NS & NS & 0,037 & NS & NS & NS & NS & NS \\
\hline $\begin{array}{l}\text { Medication } \\
\text { switch }\end{array}$ & & & & & & & & & & \\
\hline Yes & $77,3 \pm 14,8$ & $79,5 \pm 19,2$ & $57,7 \pm 25,6$ & $60,6 \pm 54,9$ & $78,0 \pm 13,7$ & $74,6 \pm 20,9$ & $67,9 \pm 30,6$ & $64,4 \pm 16,2$ & $76,5 \pm 12,9$ & $73,4 \pm 32,5$ \\
\hline No & $77,6 \pm 16,3$ & $75,5 \pm 18,0$ & $62,2 \pm 23,2$ & $66,9 \pm 16,4$ & $78,8 \pm 14,1$ & $64,3 \pm 20,0$ & $84,0 \pm 23,7$ & $75,0 \pm 16,1$ & $76,1 \pm 16,6$ & $69,9 \pm 32,2$ \\
\hline p-value & NS & NS & NS & 0,049 & NS & NS & 0,08 & 0,043 & NS & NS \\
\hline Regular treatme & & & & & & & & & & \\
\hline Yes & $76,0 \pm 16,6$ & $76,0 \pm 21,3$ & $55,6 \pm 28,0$ & $54,0 \pm 23,1$ & $78,7 \pm 14,7$ & $71,1 \pm 24,0$ & $74,5 \pm 29,8$ & $66,7 \pm 18,3$ & $73,8 \pm 15,5$ & $72,2 \pm 33,0$ \\
\hline No & $79,4 \pm 12,1$ & $81,8 \pm 10,8$ & $61,3 \pm 23,0$ & $76,9 \pm 69,5$ & $76,8 \pm 11,0$ & $73,3 \pm 16,4$ & $67,3 \pm 28,8$ & $69,2 \pm 14,8$ & $79,2 \pm 13,1$ & $72,2 \pm 31,4$ \\
\hline $\mathrm{p}$-value & NS & NS & NS & NS & NS & NS & NS & NS & NS & NS \\
\hline
\end{tabular}


*number of hospitalizations after transplant

VIT vitality; PsWB psychological well-being; RFr relations with friends; LEI leisure activities; RPa relations with parents; PhWB physical well-being; RT relations with teachers; SCH school performance; BI body image; RMS and relations with medical staff

NS: non significant; R: correlation coefficient; Bold values: p-values< 0.05; higher scores indicate higher QoL

Table 3. Factors modulating self-reported QoL of children (VSP-A): N=28 


\begin{tabular}{|c|c|c|c|c|c|c|c|}
\hline & RFa & BI & VIT & RFr & LEI & $\mathrm{SCH}$ & RMS \\
\hline \multicolumn{8}{|l|}{ Gender of the child } \\
\hline Boys & $70,4 \pm 15,3$ & $77,5 \pm 18,5$ & $82,7 \pm 20,2$ & $53,8 \pm 31,8$ & $60,7 \pm 20,1$ & $70,8 \pm 19,2$ & $67,1 \pm 29,6$ \\
\hline Girls & $59,8 \pm 20,4$ & $74,5 \pm 20,0$ & $74,4 \pm 23,1$ & $58,2 \pm 24,2$ & $55,1 \pm 26,6$ & $70,8 \pm 19,8$ & $78,1 \pm 34,2$ \\
\hline p-value & NS & NS & NS & NS & NS & NS & NS \\
\hline \multirow{2}{*}{$\begin{array}{l}\text { Age of the child (R) } \\
\text { p-value }\end{array}$} & $-0,090$ & 0,265 & $-0,150$ & 0,491 & $-0,163$ & 0,443 & $-0,073$ \\
\hline & NS & NS & NS & 0,009 & NS & 0,024 & NS \\
\hline \multicolumn{8}{|l|}{ School retardation } \\
\hline No & $74,1 \pm 12,3$ & $79,6 \pm 17,3$ & $82,8 \pm 18,9$ & $60,6 \pm 26,9$ & $58,4 \pm 19,0$ & $73,4 \pm 17,0$ & $68,2 \pm 31,9$ \\
\hline Yes & $57,3 \pm 20,3$ & $72,0 \pm 21,4$ & $74,2 \pm 24,1$ & $46,6 \pm 32,8$ & $56,8 \pm 25,8$ & $67,5 \pm 23,0$ & $73,1 \pm 31,9$ \\
\hline p-value & 0,020 & NS & NS & NS & NS & NS & NS \\
\hline Age of parent (R) & 0,100 & 0,113 & $-0,018$ & 0,435 & $-0,054$ & 0,371 & 0,135 \\
\hline p-value & NS & NS & NS & 0,021 & NS & NS & NS \\
\hline \multicolumn{8}{|l|}{ Parental marital status } \\
\hline Single & $61,3 \pm 13,9$ & $64,3 \pm 23,2$ & $66,7 \pm 33,1$ & $45,4 \pm 27,0$ & $53,5 \pm 32,3$ & $64,6 \pm 14,6$ & $36,1 \pm 28,2$ \\
\hline Couple & $68,6 \pm 18,3$ & $79,9 \pm 16,3$ & $83,7 \pm 15,7$ & $57,8 \pm 29,7$ & $60,3 \pm 19,1$ & $72,6 \pm 20,0$ & $80,8 \pm 23,6$ \\
\hline p-value & NS & NS & NS & NS & NS & NS & 0,001 \\
\hline \multicolumn{8}{|c|}{ Parent' educational level } \\
\hline$<12$ years & $62,9 \pm 20,1$ & $74,4 \pm 21,8$ & $77,1 \pm 23,0$ & $49,7 \pm 31,0$ & $58,4 \pm 25,5$ & $66,1 \pm 23,7$ & $66,0 \pm 33,8$ \\
\hline$>=12$ years & $71,7 \pm 13,1$ & $78,8 \pm 15,6$ & $83,5 \pm 19,1$ & $61,5 \pm 26,6$ & $59,4 \pm 18,3$ & $76,0 \pm 10,8$ & $75,0 \pm 28,3$ \\
\hline $\mathrm{p}$-value & NS & NS & NS & NS & NS & NS & NS \\
\hline \multicolumn{8}{|c|}{ Parent' professional status } \\
\hline Workers & $71,0 \pm 16,1$ & $78,3 \pm 19,6$ & $80,3 \pm 19,7$ & $59,2 \pm 29,4$ & $61,5 \pm 18,8$ & $75,7 \pm 17,4$ & $71,9 \pm 31,6$ \\
\hline Not workers & $59,9 \pm 18,5$ & $73,9 \pm 17,9$ & $79,5 \pm 24,7$ & $48,0 \pm 28,7$ & $54,1 \pm 27,4$ & $62,5 \pm 19,5$ & $68,3 \pm 31,1$ \\
\hline p-value & NS & NS & NS & NS & NS & NS & NS \\
\hline Siblings number $\left(\mathrm{R}^{\circ}\right)$ & 0,004 & 0,483 & 0,131 & $-0,216$ & 0,210 & $-0,119$ & 0,246 \\
\hline p-value & NS & 0,014 & NS & NS & NS & NS & NS \\
\hline \multicolumn{8}{|c|}{ Nature of the transplant } \\
\hline Liver & $71,1 \pm 12,1$ & $78,6 \pm 18,6$ & $82,4 \pm 21,0$ & $53,1 \pm 35,4$ & $60,5 \pm 22,6$ & $71,3 \pm 17,7$ & $63,3 \pm 37,5$ \\
\hline Kidney & $65,7 \pm 20,8$ & $78,8 \pm 17,1$ & $82,5 \pm 24,6$ & $56,1 \pm 27,9$ & $64,1 \pm 18,0$ & $73,8 \pm 16,1$ & $81,7 \pm 19,6$ \\
\hline Heart & $62,5 \pm 20,6$ & $70,2 \pm 22,5$ & $72,9 \pm 16,8$ & $57,1 \pm 23,6$ & $48,9 \pm 26,2$ & $66,1 \pm 25,7$ & $63,9 \pm 33,6$ \\
\hline p-value & NS & NS & NS & NS & NS & NS & NS \\
\hline \multirow{2}{*}{$\begin{array}{l}\text { Age at transplant (R) } \\
\text { p-value }\end{array}$} & 0,072 & 0,161 & $-0,060$ & 0,430 & 0,023 & 0,225 & $-0,005$ \\
\hline & NS & NS & NS & 0,025 & NS & NS & NS \\
\hline \multirow{2}{*}{$\begin{array}{l}\text { Delay from transplant } \\
\text { p-value }\end{array}$} & $-0,021$ & 0,071 & $-0,151$ & 0,249 & $-0,230$ & 0,415 & $-0,009$ \\
\hline & NS & NS & NS & NS & NS & 0,031 & NS \\
\hline \multicolumn{8}{|l|}{ Graft rejection } \\
\hline Yes & $70,0 \pm 20,5$ & $74,7 \pm 20,9$ & $80,4 \pm 21,0$ & $54,5 \pm 36,3$ & $54,2 \pm 24,2$ & $70,8 \pm 22,8$ & $75,0 \pm 28,9$ \\
\hline No & $64,8 \pm 15,6$ & $78,2 \pm 17,1$ & $79,7 \pm 22,6$ & $54,3 \pm 24,3$ & $63,6 \pm 20,5$ & $70,8 \pm 16,1$ & $66,7 \pm 33,0$ \\
\hline $\mathrm{p}$-value & NS & NS & NS & NS & NS & NS & NS \\
\hline \multicolumn{8}{|l|}{ Reoperation } \\
\hline Yes & $68,2 \pm 10,5$ & $83,1 \pm 15,7$ & $82,6 \pm 22,1$ & $54,6 \pm 29,0$ & $65,0 \pm 22,7$ & $75,0 \pm 8,83$ & $60,2 \pm 37,9$ \\
\hline No & $66,3 \pm 20,6$ & $73,5 \pm 19,6$ & $78,6 \pm 21,1$ & $55,5 \pm 30,1$ & $55,5 \pm 21,6$ & $68,8 \pm 22,4$ & $76,0 \pm 26,0$ \\
\hline p-value & NS & NS & NS & NS & NS & NS & NS \\
\hline \multicolumn{8}{|l|}{ Radiointervention } \\
\hline Yes & $64,0 \pm 19,2$ & $72,9 \pm 18,4$ & $79,2 \pm 21,6$ & $52,6 \pm 31,3$ & $54,2 \pm 23,0$ & $66,2 \pm 21,5$ & $77,6 \pm 27,2$ \\
\hline No & $72,1 \pm 13,7$ & $81,3 \pm 18,5$ & $79,4 \pm 21,6$ & $56,5 \pm 24,9$ & $69,9 \pm 17,6$ & $77,8 \pm 10,4$ & $54,6 \pm 33,1$ \\
\hline p-value & NS & NS & NS & NS & NS & NS & NS \\
\hline \multicolumn{8}{|c|}{ Last residual treatment level } \\
\hline Satisfactory & $66,7 \pm 17,7$ & $80,5 \pm 17,5$ & $81,4 \pm 18,5$ & $54,9 \pm 29,6$ & $60,2 \pm 20,8$ & $75,0 \pm 16,6$ & $72,5 \pm 25,1$ \\
\hline Not satisfactory & $68,4 \pm 12,8$ & $71,8 \pm 18,2$ & $81,4 \pm 26,6$ & $53,8 \pm 34,3$ & $63,0 \pm 20,1$ & $62,5 \pm 20,4$ & $71,4 \pm 36,0$ \\
\hline p-value & NS & NS & NS & NS & NS & NS & NS \\
\hline \multicolumn{8}{|l|}{ Medication switch } \\
\hline Yes & $66,0 \pm 17,0$ & $78,9 \pm 19,0$ & $79,3 \pm 20,7$ & $49,9 \pm 31,4$ & $53,1 \pm 22,0$ & $73,0 \pm 13,3$ & $69,9 \pm 30,9$ \\
\hline No & $69,5 \pm 19,6$ & $69,6 \pm 18,4$ & $81,9 \pm 23,4$ & $68,4 \pm 17,9$ & $73,3 \pm 15,0$ & $65,6 \pm 28,9$ & $71,9 \pm 32,7$ \\
\hline p-value & NS & NS & NS & NS & 0,038 & NS & NS \\
\hline \multicolumn{8}{|l|}{ Regular treatment } \\
\hline Yes & $66,2 \pm 18,0$ & $70,0 \pm 19,3$ & $75,1 \pm 23,7$ & $58,3 \pm 29,9$ & $54,7 \pm 24,0$ & $68,4 \pm 23,0$ & $70,3 \pm 31,0$ \\
\hline No & $68,5 \pm 17,4$ & $88,3 \pm 10,4$ & $89,0 \pm 12,0$ & $49,6 \pm 28,5$ & $66,4 \pm 16,5$ & $75,0 \pm 8,3$ & $70,8 \pm 32,2$ \\
\hline p-value & NS & 0,016 & NS & NS & NS & NS & NS \\
\hline
\end{tabular}

$\mathrm{RFa}$ relations with parents/family; BI body image/self-esteem; VIT vitality; RFr relations with friends; LEI leisures; SCH school performance; RMS relations with medical staff; higher scores indicate higher QoL

${ }^{\circ} \mathrm{R}$ : correlation's coefficients

Bold values: $p$-values $<0.05$ 
Figures

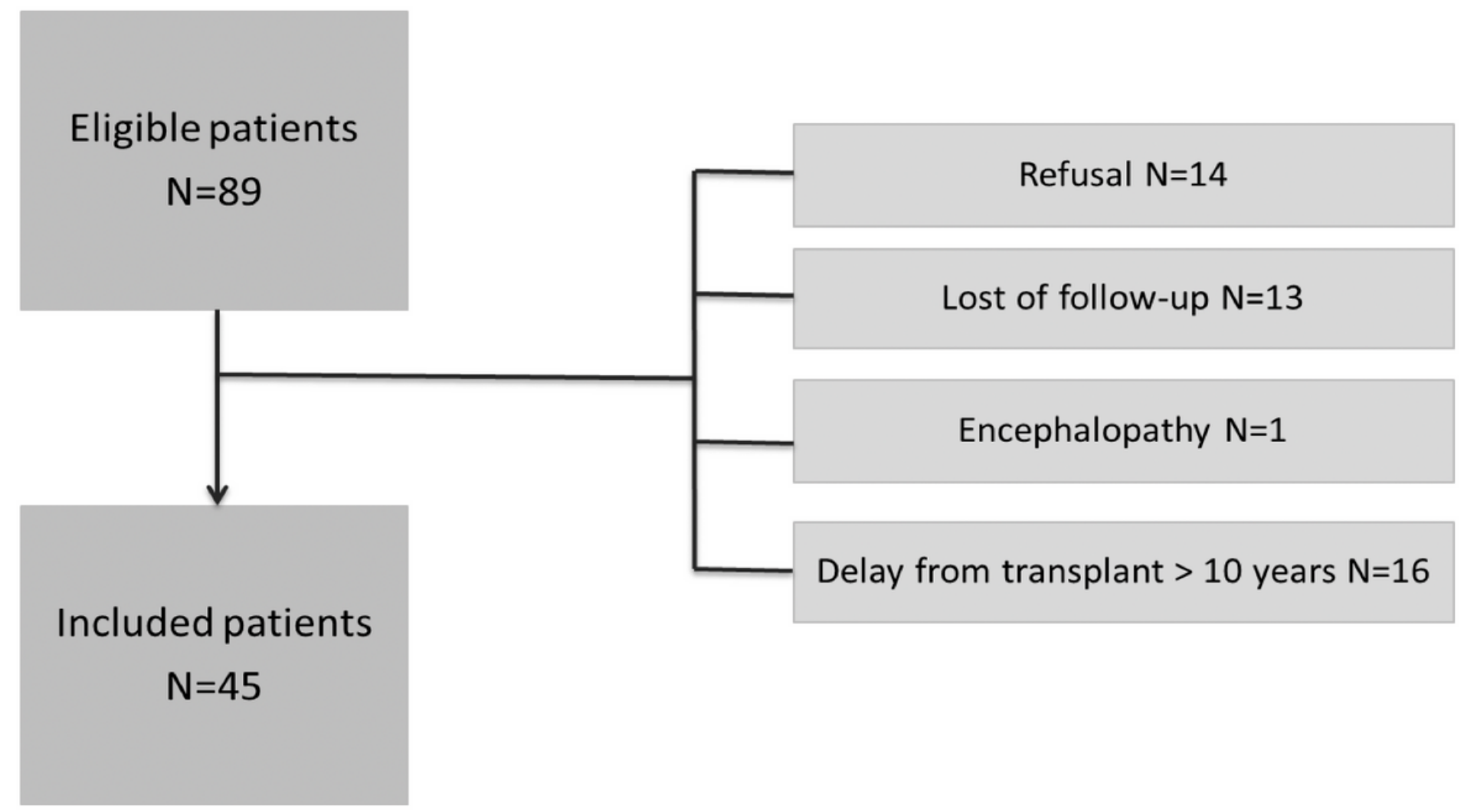

Figure 1

Chart 


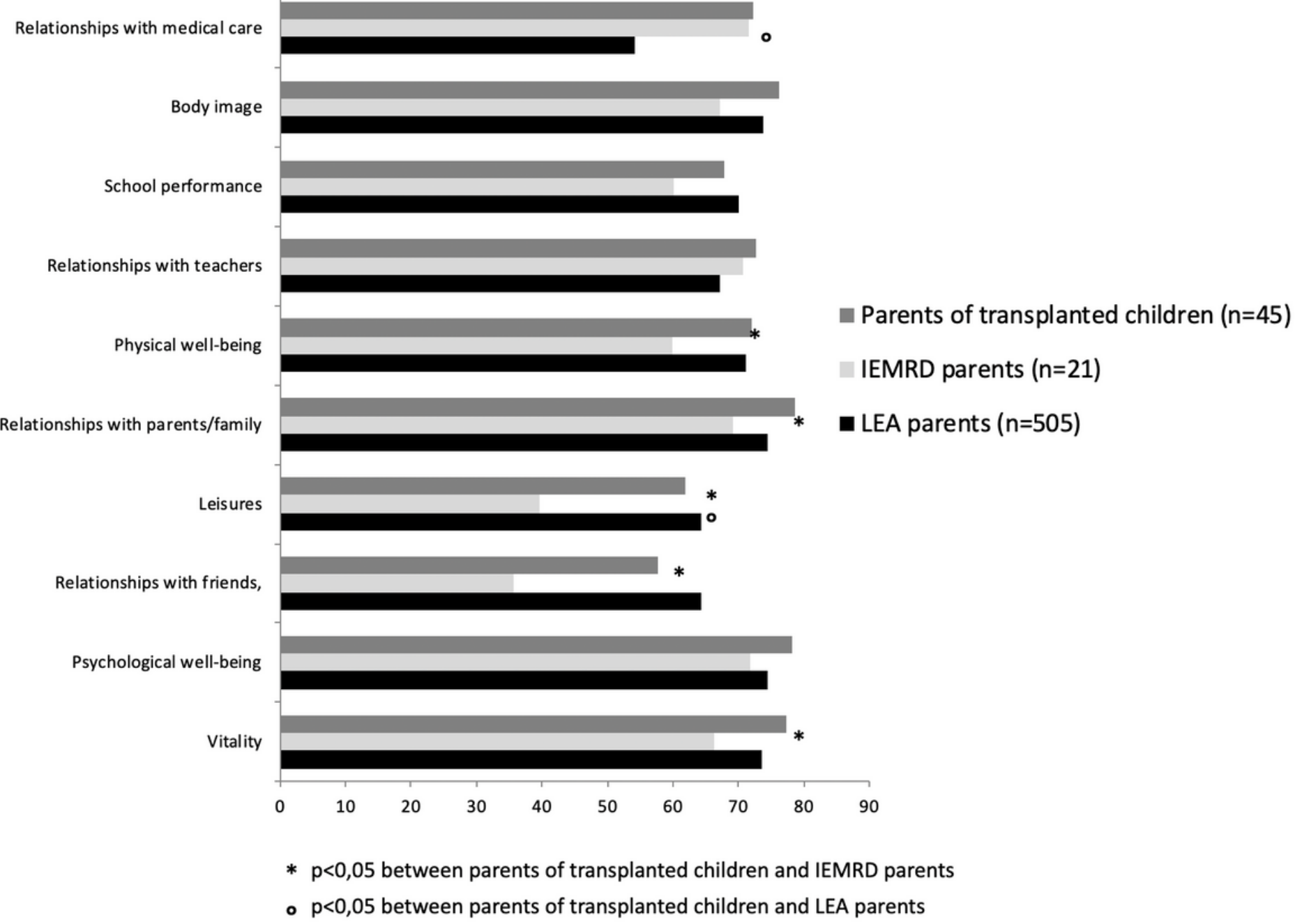

Figure 2

Quality of life of transplanted children reported by their parents 


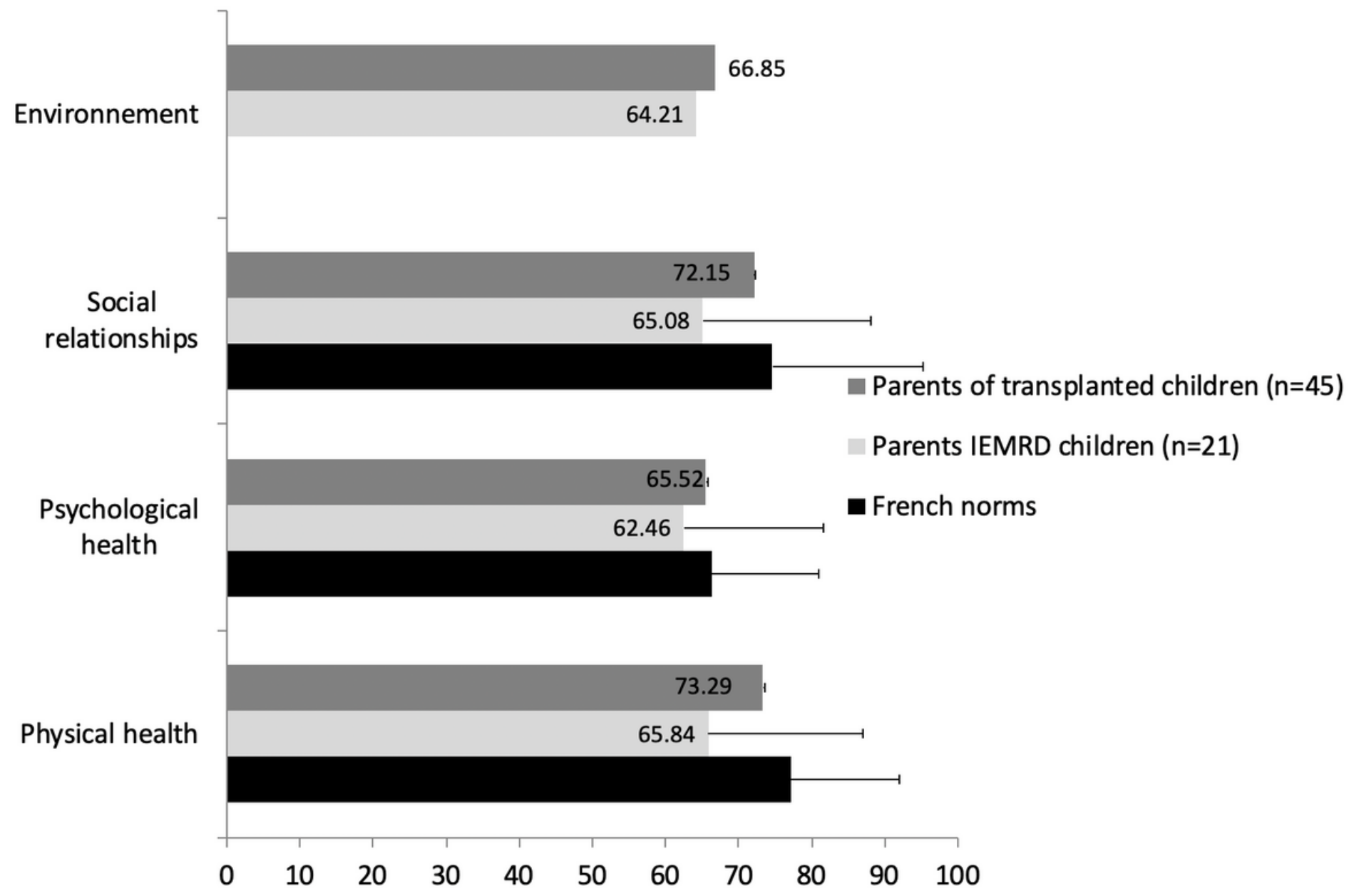

Figure 3

Quality of life of parents of transplanted children Comparisons of WhoQoL scores between the parents of transplanted children and IEMRD parents and French age-sex-crossed norms

\section{Supplementary Files}

This is a list of supplementary files associated with this preprint. Click to download.

- Additionalfiles.docx 